Relations industrielles

Industrial Relations

\title{
Social Commitment, Rev. Everett J. Morgan, S.J., McCutchan Publishing Corporation, California, 1967, 258 pages.
}

\section{Marc-Aurèle Lavoie}

Volume 22, numéro 3, 1967

URI : https://id.erudit.org/iderudit/027830ar

DOI : https://doi.org/10.7202/027830ar

Aller au sommaire du numéro

Éditeur(s)

Département des relations industrielles de l'Université Laval

ISSN

0034-379X (imprimé)

1703-8138 (numérique)

Découvrir la revue

Citer ce compte rendu

Lavoie, M.-A. (1967). Compte rendu de [Social Commitment, Rev. Everett J. Morgan, S.J., McCutchan Publishing Corporation, California, 1967, 258 pages.] Relations industrielles / Industrial Relations, 22(3), 458-458.

https://doi.org/10.7202/027830ar

Tous droits réservés (C) Département des relations industrielles de l'Université Laval, 1967
Ce document est protégé par la loi sur le droit d'auteur. L'utilisation des services d'Érudit (y compris la reproduction) est assujettie à sa politique d'utilisation que vous pouvez consulter en ligne.

https://apropos.erudit.org/fr/usagers/politique-dutilisation/ 
1.-le manque de prestige de lo médecine industrielle.

2.-linfluence des structures industrielles sur la pratique médicale.

3.-la difficulté de définir les rôles du personnel médical et leurs relations avec les autres employés.

4.- - le rôle du syndicat dans la protection de la santé de ses membres.

\section{Jean SEXTON}

Social Commitment, Rev. Everett J. Morgan, S.J., McCutchan Publishing Corporation, Colifornio, 1967, 258 poges

Ce volume est fait ò l'intention des écoles secondaires, des collèges et du travail poursuivi à l'intérieur de groupes où les cours donnés et les sujets débottus ont une résonnance sur les problèmes nombreux et complexes dans le domaine social, économique et politique de notre monde contemporain. Les nombreux problèmes abordés par l'outeur sont traités selon une méthodologie ofin d'ottirer l'attention des jeunes et pour foire lumière sur certains domaines spécifiques à notre société où se rencontrent les désordres socio-économiques les plus sérieux.

La doctrine sociale de l'Eglise est à lo source de ce volume qui a pour objectif de clarifier nos responsabilités socioles envers nos voisins et de s'engager ò une réforme sociale véritable. En plus de se reférer constomment oux encycliques Rerum Novarum de Leon XIII, Quadrogesimo Anno de Pie XI, Mater et Magistra et Pacem in Terris de Jean XXIII, l'outeur place ò la fin de choque portie une bibliographie considérable de livres et d'articles se rapportant aux sujets discutés dans cette partie.

Les différents sujets obordés par l'auteur sont dons l'ordre: le peuple de Dieu et le travail dans le monde; le peuple de Dieu et l'éducation; le peuple de Dieu et la société politique; le peuple de Dieu et les droits et libertés civiles; le peuple de Dieu et l'ordre éconornique; le peuple de Dieu et la société internationale.

Ce volume o été écrit pour servir les intérêts de l'Eglise et de l'humanité. Quoique les documents du concile emploient le terme * amour * fréquernment et à propos, il est évident oussi que le mot « justice " apparait souvent dons les Constitutions, dans les Décrets et dans les Déclarations de Vaticon 11. L'auteur cherche donc ì montrer que les nécessités socioles doivent être parmi les devoirs les plus importants de I'homme maderne et qu'une attention spéciole doit leur être portée.

\section{Marc-Aurèle LAVOIE}

\section{PUBLICATIONS RECENTES}

\section{GÉNÉRALITÉS}

\& Le fédérolisme conadien d̀ la recherche d'un nouvel équilibre par Dale C. Thompson, Analyse \& Prévision, Tome 1II, No 5 , Moi 1967, pp. 327-343.

«Problems of Bilingualism $\gg$ by John Macnamaro, The Journal of Social Issues, Vol. XXIII, No 2, April 1967, pp. 58-78.

\& Symposium on Rotes of Return to Investment in Educotion $\gg$ The Journal of Human Resources, Vol. II, No 3, Summer 1967, pp. $291-375$.
\&Autogestion et démocratie p par Yvon Bourdet, Autogestion, Cohier No 2, avril 1967, pp. 45-65.

* L'outogestion et les manogers par René Loureau, Autogestion, Cohier No 2, ovril 1967, pp. 65-79.

\&L'outogestion ouvrière en Yougoslovie > par Joze Goricar, Autogestion, Cohier No 2 , avril 1967, pp. 95-105.

\& Un faux dilemme: intéressement motériel ou auto-gestion \$ par Joseph Fisero, Autogestion, Cohier No 2, Avril 1967, pp. 121. 137. 